Coming home may hurt: risk factors for mental ill health in US reservists after deployment in Iraq. BJP, 198, 136-142. The following disclaimer applies: The opinions or assertions contained herein are the private views of the author, and are not to be construed as official, or as reflecting true views of the Department of the Army or the Department of Defense.

doi: $10.1192 /$ bjp.198.3.241

\section{psychiatry in pictures}

\title{
The man behind Philippe Pinel: Jean-Baptiste Pussin (1746-1811)
}

Jean-Pierre Schuster, Nicolas Hoertel and Frédéric Limosin

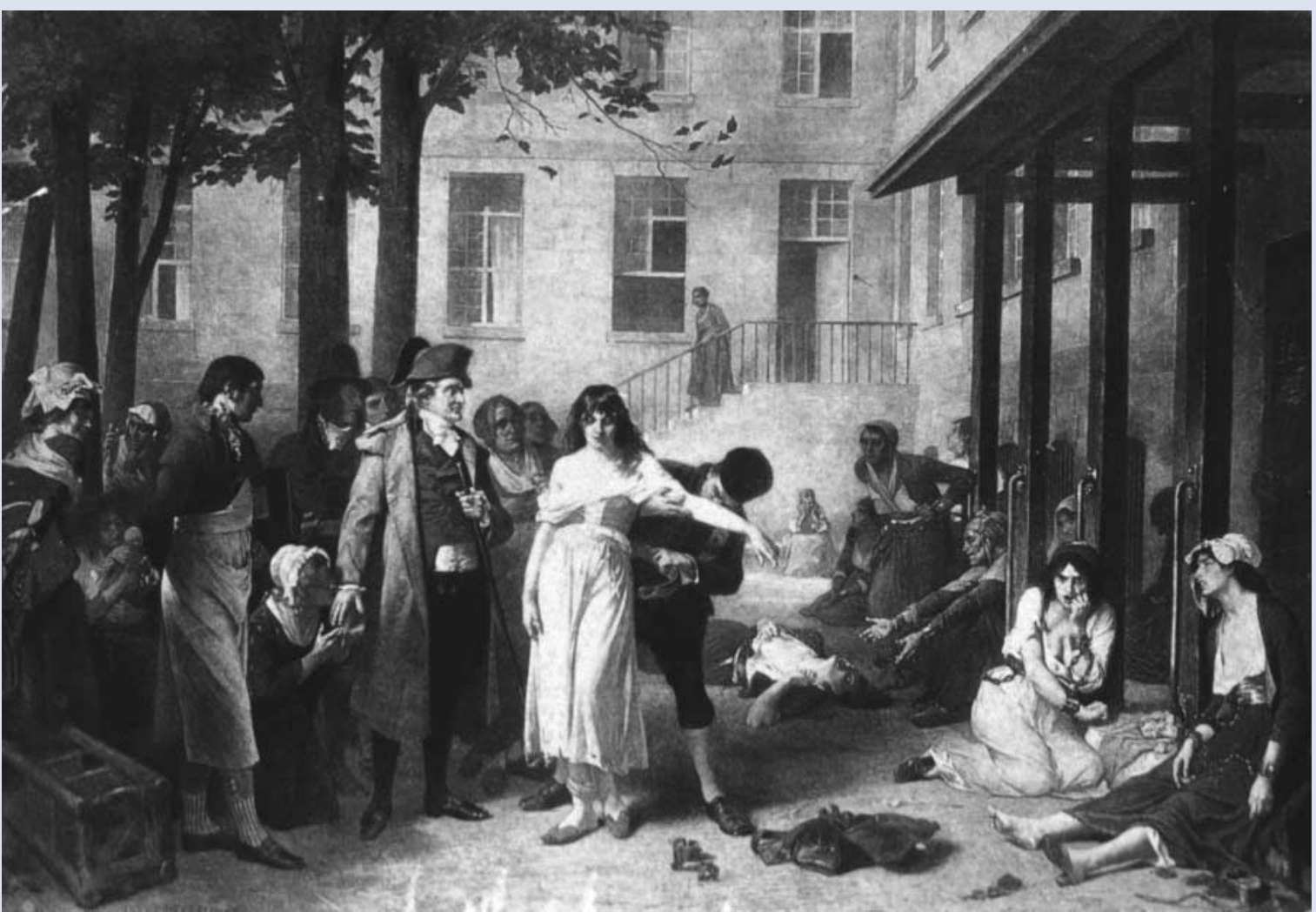

Dr Pinel in the courtyard of the Salpêtrière. Gravure by Goupil after painting by Robert-Fleury, 1876. From 'Images from the History of Medicine' (National Library of Medicine, USA)

At the beginning of the third French Republic, Tony-Robert Fleury painted Pinel Frees the Madwomen at the Salpêtrière. Fifty years after the death of Pinel, the painting strengthens his legend as the 'liberator of the insane'. Fleury depicts Pinel supervising the removal of chains from an inmate. A woman inmate stands in the centre surrounded by other people who give movement to the composition. A man, possibly Jean-Baptiste Pussin, removes the last of the chains from around her waist, while another woman, possibly Pussin's wife, Marguerite Jubline (1754-?), watches on with concern.

In his Treatise on Insanity, Pinel acknowledged his debt to Pussin and to Madame Pussin. He credits Pussin for liberating the insane from their chains as an empirical application of the 'moral treatment'.

Pussin was born in September 1745 to a family of tanners. He was hospitalised at Bicêtre in 1771, suffering from scrofula. In 1780 he had been declared successfully treated and was recruited to work at the hospice. In 1785, he became 'governor' of the ward for incurable psychiatric patients (l'emploi Saint Prix) and held this post until 1802. He developed a knowledge imbued with great humanism. Concerned about the well-being of his patients, in 1791 he increased the daily ration of bread at a time when most of the patients were dying of exhaustion.

Between 1793 and 1795, Pinel had served as physician to the Bicêtre infirmaries. The meeting of the two men was the source of fruitful collaboration. Pinel welcomed the practical wisdom of a layman and adopted his empirical evidence. He appreciated Pussin's contribution so greatly that he arranged to have a position created for him at the Salpêtrière, where he himself was working. Pussin arrived at the Salpêtrière in 1802 and spent the last 10 years of his life as Pinel's colleague. He died on 7 April 1811.

Fleury's painting has long been hung in the amphitheatre of the Salpêtrière, where Charcot gave his lectures. Today it adorns the entrance of the Library Charcot in the same hospital.

Jean-Pierre Schuster, Nicolas Hoertel and Frédéric Limosin, Assistance Publique-Hôpitaux de Paris, Department of Psychiatry, Corentin Celton Hospital, and Paris Descartes University, France. 